\title{
Impact of Mediterranean diet education versus posted leaflet on dietary habits and serum cholesterol in a high risk population for cardiovascular disease
}

\author{
Wanda JE Bemelmans ${ }^{1, *}$, Jan Broer ${ }^{2}$, Jeanne HM de Vries ${ }^{3}$, Karin FAM Hulshof ${ }^{4}$, \\ Jo F May ${ }^{5}$ and Betty Meyboom-de Jong ${ }^{1}$ \\ 'Department of General Practice, University of Groningen, Anton Deusinglaan, 9713 AW Groningen, \\ the Netherlands: ${ }^{2}$ Regional Public Health Service, GGD Groningen, Postbus 584, 9700 AN Groningen, \\ the Netherlands: ${ }^{3}$ Department of Human Nutrition and Epidemiology, Wageningen Agricultural University, \\ Postbus 8129, 6700 EV Wageningen, The Netherlands: ${ }^{4}$ TNO Nutrition and Food Research Institute, \\ Postbus 360, 3700 AJ Zeist, the Netherlands: ${ }^{5}$ Department of Cardiology, Groningen University Hospital, \\ Postbus 30001, 9700 RB Groningen, the Netherlands
}

Submitted 1 October 1999: Accepted 7 January 2000

\begin{abstract}
Objective: To investigate the impact of intensive group education on the Mediterranean diet on dietary intake and serum total cholesterol after 16 and 52 weeks, compared to a posted leaflet with the Dutch nutritional guidelines, in the context of primary prevention of cardiovascular disease (CVD).

Design: Controlled comparison study of an intervention group given intensive group education about the Mediterranean diet and a control group of hypercholesterolaemic persons given usual care by general practitioners (GPs).

Setting: A socioeconomically deprived area in the Netherlands with an elevated coronary heart disease (CHD) mortality ratio.

Subjects: Two hundred and sixty-six hypercholesterolaemic persons with at least two other CVD risk factors.

Results: After 52 weeks, the intervention group decreased total and saturated fat intake more than the control group (net differences were 1.8 en\% (95\%CI 0.2-3.4) and 1.1 en\% (95\%CI 0.4-1.9), respectively). According to the Mediterranean diet guidelines the intake of fish, fruit, poultry and bread increased in the intervention group, more than in the control group. Within the intervention group, intake of fish $(+100 \%)$, poultry $(+28 \%)$ and bread $(+6 \%)$ was significantly increased after 1 year $(P<0.05)$. The intensive programme on dietary education did not significantly lower serum cholesterol level more $(-3 \%)$ than the posted leaflet $(-2 \%)$ (net difference $0.06 \mathrm{mmol}^{-1}, 95 \% \mathrm{CI}-0.10$ to 0.22 ). Initially, the body mass index (BMI) decreased more in the intervention group, but after 1 year the intervention and control group gained weight equally $(+1 \%)$.

Conclusions: Despite beneficial changes in dietary habits in the intervention group compared with the control group, after 1 year BMI increased and total fat and saturated fat intake were still too high.
\end{abstract}

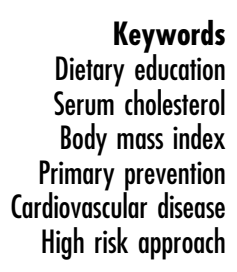

Coronary heart disease is the leading cause of death and a major cause of morbidity in the Netherlands. Thirty-nine per cent of all deaths are due to CVD and 39\% of CVD mortality is due to $\mathrm{CHD}^{1}$. In the northeastern region of the Netherlands, the age-standardized mortality ratios for total mortality, CVD, CHD and acute myocardial infarction were $6 \%, 12 \%, 28 \%$ and $47 \%$, respectively, above the national average in the period $1987-1993^{2-5}$. In this area, unemployment is high and the average income per capita is $10 \%$ below the national average ${ }^{6}$. The majority of the surplus CVD risk in socioeconomically deprived population groups is mediated by established
CVD risk factors ${ }^{7}$. Two representative population-based health surveys (1994 and 1998) indicated a higher prevalence of smoking (36\%) and being overweight (43\% with $\mathrm{BMI} \geqslant 25 \mathrm{~kg} \mathrm{~m}^{-2}$ ) in the study area. The comparative national figures are $34 \%$ and $40 \%$, respectively ${ }^{8}$.

Due to the combination of high CVD mortality and a high prevalence of being overweight and smoking, a dietary intervention study was planned focusing on health promotion for persons at high risk for CVD in this area. This primary prevention project is the MARGARIN study, abbreviated from Mediterranean alpha-linolenic enriched Groningen dietary intervention study. Participants have 
hypercholesterolaemia $\left(6.0-8.0 \mathrm{mmol}^{-1}\right)$ and at least two other CVD risk factors.

Our study was inspired by the Lyon Diet Heart Study (LDHS) which was a prospective secondary prevention trial in patients with a myocardial infarction. In that study, education about Mediterranean diet habits and supplementation of an $\alpha$-linolenic acid-enriched margarine resulted in a $70 \%$ reduction in non-fatal acute myocardial infarction and cardiovascular death ${ }^{9}$. The LDHS researchers concluded that a Mediterranean $\alpha$-linolenic acid-rich diet protected against CHD more efficiently than the usual prudent diet prescribed to CHD patients ${ }^{10}$. Contrary to the LDHS, the design of the MARGARIN study makes it possible to investigate separately the effect of intensive education about the Mediterranean diet (single blind) and supplementation of an $\alpha$-linolenic-enriched margarine (double blind).

This article presents the study design and preliminary results of the intensive education programme after 1 year of follow-up. The intensive education about the Mediterranean diet is compared with care as usual by GPs for hypercholesterolaemic persons in Dutch primary health care. According to the treatment guidelines for GPs, hypercholesterolaemic persons at high risk for CHD receive a leaflet with the Dutch national food guidelines, in order to decrease (saturated) fat intake. However, implementation of treatment standards by GPs is complicated, because they have little time and limited skills available for modification of nutritional behaviour ${ }^{11,12}$. Furthermore, there is conflicting evidence about the effectiveness of individual dietary counselling in reducing serum cholesterol levels ${ }^{13-15}$. Therefore, in the MARGARIN study, we chose a group approach applied in a primary health care setting.

This paper describes the baseline characteristics and compares the nutrient and food intake of a high risk population with the average Dutch dietary intake, according to the national food consumption survey ${ }^{16}$. Furthermore, we investigate if intensive group education on Mediterranean diet habits by a dietician is more effective in changing dietary behaviour and lowering serum total cholesterol after 1 year, than care as usual.

\section{Materials and methods}

\section{Study design and endpoints}

The groups B2 and B3 (intervention group) received intensive group education on Mediterranean dietary habits, and the groups B1 and A (control group) obtained care as usual (Table 1). To minimize cross-over of information, the participants of the intervention group were recruited in one county and the participants of the control group were recruited in neighbouring counties. Due to the central location the intervention county was not randomly identified. The whole study area is culturally and socioeconomically homogeneous.

All participants received either an $\alpha$-linolenic acidenriched margarine or a linoleic acid-rich margarine. The allocation of the margarines was implemented by an independent research organization (the Trial Coordination Center, Groningen). This was done in accordance to a predefined randomization schedule. The schedule was generated by computer using a random number generator to assign the participants to one of the margarines. Randomization was performed into two strata, namely the intervention group and the control group (Table 1). In the case of more than one participant per household, the allocation of the margarines was forced to be identical for each household member. The margarines were supplied until November 1999. The medical ethical committee of Groningen University Hospital approved the study design.

The primary endpoint of the study is the rate of CVD events and CVD death, 4 years after baseline. Secondary endpoints are the levels of CVD risk factors, calculated risk of developing CHD according to the Framingham CHD risk function, fatty acid profiles of thrombocyte and cholesteryl ester, fibrinolytic and thrombolytic parameters, and changes in dietary behaviour.

\section{Sample size}

Before the start of the study, the sample size was established on the basis of an estimated difference in $\alpha$-linolenic acid content of the cholesteryl ester. With a control group of 100 persons (no education and linoleic acid-rich

Table 1 Design of the MARGARIN study and number of participants according to study protocol

\begin{tabular}{|c|c|c|c|c|}
\hline & \multicolumn{2}{|c|}{ Control group } & \multicolumn{2}{|c|}{ Intervention group } \\
\hline & $A$ & B1 & B2 & B3 \\
\hline $\begin{array}{l}\text { Mediterranean nutrition education }(+) \text { vs } \\
\text { care as usual }(-)\end{array}$ & - & - & + & + \\
\hline $\begin{array}{l}\text { Alpha-linolenic acid-enriched margarine }(+) \\
\text { vs linoleic acid-rich margarine }(-)^{*}\end{array}$ & - & + & - & + \\
\hline Number of participants & 100 & 50 & 50 & 50 \\
\hline
\end{tabular}

* The margarines have equal amounts of polyunsaturated fatty acids. 
margarine) and an intervention group of 50 (education and $\alpha$-linolenic acid-rich margarine) a difference of $0.10 \mathrm{mmol}^{-1}$ would be significant (5\% type 1 error twosided). In the LDHS a difference of $0.25 \mathrm{mmoll}^{-1}$ was found.

\section{Participants and selection}

Inclusion criteria were a mean of two serum cholesterol measurements between 6 and $8 \mathrm{mmoll}^{-1}$, together with at least two of the following CVD risk factors: high blood pressure (diastolic $\geqslant 95 \mathrm{mmHg}$ and/or systolic $\geqslant 160 \mathrm{mmHg}$ ) or use of antihypertensive medication; BMI $\geqslant 27 \mathrm{~kg} \mathrm{~m}^{-2}$; smoking; diagnosis of CHD or a first-degree relative with a CHD history prior to the age of 60 years. Exclusion criteria were age below 30 or over 70 years, diabetes mellitus, hypothyroidism, and the use of acetylsalicylic acid, anticoagulant or cholesterol-lowering drugs.

Potential participants with at least two CVD risk factors were invited for a serum cholesterol measurement. Three initiatives were developed to identify potential participants. First, all inhabitants aged over 30 years in two counties (Winschoten and Scheemda) received a written invitation to participate in a blood pressure screening programme. The number of persons with at least two CVD risk factors was 785, and $16 \%$ eventually participated. Nonresponders $(n=192)$ and responders who had at least one serum cholesterol measurement $(n=593)$ did not differ in age, BMI, percentage of hypertension and use of antihypertensive medication. Second, registration systems of one GP and three pharmacies in these two counties were screened for patients on antihypertensive drugs ( $n=1163$, participation $=11 \%$ ). Third, a local radio programme discussed the MARGARIN project and invited potential participants to contact the researchers.

Written informed consent was obtained from 282 persons (11\% volunteered via the radio programme). Before baseline examinations 14 persons dropped out. Further, two persons were excluded because of diabetes mellitus, discovered at baseline examination. Before the first follow-up (T16) three persons dropped out and before the third examinations (T52) six persons dropped out for diverse reasons.

\section{Initial examination and follow-up measurements}

In November 1997 the baseline examination was conducted, in the early morning after an overnight fast. Within 2 weeks, all subjects were investigated at the regional hospital. We determined total serum cholesterol, high density lipoprotein (HDL) cholesterol, triacylglycerol level, fibrinogen, von Willibrand factor, tPA (tissue plasminogen factor) antigen, and the fatty acid composition of the cholesteryl ester and the thrombocyte membrane. Only at baseline examinations did we determine the C-reactive protein (CRP), thyroid-stimulating hormone (TSH), glucose and leucocyte concentration, to control for underlying diseases. A standardized validated medical questionnaire was used to establish the presence of CVD, the family history of CHD, smoking habits, coffee and tea consumption, and exercise ${ }^{17}$. Body weight was measured without shoes and heavy clothing. Blood pressure was measured in the sitting position. Height was measured during the study in March 1998, and was assumed to be equal at baseline. Participants completed a food frequency questionnaire 3 weeks before baseline examination.

Follow-up examinations were conducted after 16 weeks (T16) and after 52 weeks (T52), and will be done at 104, 156 and 208 weeks.

\section{Dietary assessment}

Dietary intake was assessed by a self-administered semiquantitative food frequency questionnaire, called the FFQ-ALA. The FFQ-ALA is based on two validated questionnaires, measuring total fat and fatty acid intake ${ }^{18}$, or antioxidant and macronutrient intake ${ }^{19}$. To achieve the specific objectives of the MARGARIN study, the composition of several product items was changed. The FFQ-ALA aims to accurately assess $\alpha$-linolenic and linoleic acid intake. At baseline, Pearson correlation coefficients between reported intake of $\alpha$-linolenic and linoleic acid and the corresponding content of the cholesteryl ester was $r=0.38$ and $r=0.21 \quad(P<0.01)$, respectively. Further, the FFQ-ALA determines the intake of total energy, fatty acids, alcohol and dietary fibre reasonably well. Within the study population a pilot validation study was performed in a randomly stratified, age- and sex-adjusted sample $(n=43)$. Pearson correlation coefficients between assessment by the FFQ-ALA and by a 3-day 24-hour recall method were: energy intake $(r=0.76)$, total fat as percentage of energy $(r=0.66)$, saturated fatty acids (SFA) $(r=0.51)$, monounsaturated fatty acids (MUFA) $(r=0.52)$, polyunsaturated fatty acids (PUFA) $(r=0.70)$, alcohol $(r=0.72)$ and dietary fibre in grams per day $(r=0.74)$. To establish adherence to the Mediterranean diet the FFQ-ALA provides data about food groups important in the Mediterranean diet.

The FFQ-ALA consists of 165 food items, plus 12 questions about the amount of added fat and 10 questions to determine portion sizes more accurately. The consumption frequency of each item is reported per day, week or month. Average portion sizes were assigned. In total over 650 foods contribute to the 165 items and the weighed item composition is based on the Dutch national food consumption survey ${ }^{20}$. The questionnaires were checked for completeness and accuracy, and where necessary participants were contacted for clarification. Nutrient composition of the foods was obtained from the Dutch NEVO 1996 table $^{21}$. Data on $\alpha$-linolenic content were provided by a report from the National Institute of Public Health and the Environment ${ }^{22}$, by the Dutch NEVO Foundation and by analyses from the Department of 
Human Nutrition and Epidemiology of the Agricultural University in Wageningen ${ }^{23}$. For foods with no information on $\alpha$-linolenic acid content, we estimated the levels by comparison to similar foods. The questionnaires were processed with the nutritional software package KOMEET ${ }^{\circledR}$, developed by the Department of Human Nutrition and Epidemiology of Wageningen Agricultural University. Data entry was double checked.

\section{Dietary education intervention}

The intervention group was subdivided into groups of 10 persons. Participants and their partners were invited for three meetings of 2 hours each. The meetings were organized in February and March 1998, before the first follow-up investigation (T16). The detailed content of the education programme is described elsewhere ${ }^{24}$. In short, the first session aimed to raise consciousness about risk factors for CHD and to increase knowledge of a healthy Mediterranean diet. Concrete nutritional guidelines and daily intake were explained: 5-7 slices of bread, $400 \mathrm{~g}$ vegetables, two pieces of fruit, fish at dinner twice a week, less red meat, less fat cheese and less eggs. One or two alcohol consumptions per day were advised when persons were already regular alcohol consumers. Because the Mediterranean diet as described in the LDHS is low in calcium, according to the Dutch guidelines for a healthy diet, an additional 2-3 dairy products per day were allowed. Further, we encouraged the use of the project margarine and the use of $\alpha$-linolenic acid-rich food products. The second session intended to establish a positive attitude towards the Mediterranean diet, and the third session aimed to improve skills in preparing a Mediterranean diet. At the third meeting a short questionnaire was completed on consumption frequencies of Mediterranean food products. The results were used to provide the participants feedback in an individual letter about their adherence to the Mediterranean nutritional guidelines. Four booklets with core information about the education programme were handed out and sent to participants who did not attend the meetings.

The control group received care as usual in the form of a leaflet with the Dutch guidelines for healthy diet. These guidelines differ from the Mediterranean diet guidelines in the consumption of alcohol (Dutch guideline: 'be restrictive with alcohol consumption'). Furthermore, the Mediterranean diet advice on consumption of vegetables and fish is twice as much as recommended in the Dutch guidelines. Therefore, we paid special attention to the guideline about fish intake by distributing a separate leaflet with information on several aspects of fish consumption in September 1998.

\section{Laboratory analyses}

Serum total cholesterol, HDL cholesterol and triglycerides (without blanking) were determined by enzymatic methods on a Vitros 950 (Ortho-Clinical Diagnostics,
Rochester, NY, USA). HDL cholesterol was isolated by the precipitation of low and very low density lipoproteins with dextran sulphate and magnesium chloride. The plasma cholesteryl ester fatty acid composition was determined with our previously described method ${ }^{25}$. Briefly, total lipids were isolated from plasma by organic solvent extraction. The cholesteryl esters were isolated by solid phase extraction using an aminopropyl-silica column and converted into their methyl esters by transmethylation. The methyl esters were isolated by organic solvent extraction and injected into a gas chromatograph with flame ionization detection. Peak areas were recorded and converted into mol per 100 mol fatty acids.

\section{Statistical analyses}

Means and standard deviations were computed with the statistical package SPSS $6.0^{26}$. Differences between the intervention and control groups were tested for significance $(P<0.05)$ with the unpaired Student's $t$-test (continuous variables) or chi-square test (categorical variables). Serum cholesterol level, BMI and the nutrient intakes were normally distributed. Differences in consumption of food products (not normally distributed) between the intervention and control groups were tested for significance with the Mann-Whitney U-test.

Differences between measurements in time and between the intervention and control groups were tested with the paired Student's $t$-test or Wilcoxon matched-pairs signedranks test (food products). The differences between the intervention and control groups in changes of food intake were also investigated with analysis of covariance to adjust for baseline food intake. Tables 3 and 4 only include persons with complete measurements at three points in time. Pearson and Spearman correlation coefficients were computed to assess associations between variables.

\section{Results}

\section{Baseline characteristics}

In the control group more men (49\%) were included than in the intervention group (37\%) $(P<0.05)$. Where relevant, results have been stratified for gender. Women in the intervention group had higher serum triacylglycerol concentration $\left(2.0 \pm 0.9 \mathrm{mmoll}^{-1}\right)$ than women of the control group $\left(1.7 \pm 0.8 \mathrm{mmol}^{-1}\right)$. No differences in CVD risk factors existed between the intervention and control groups (Table 2). Mean BMI in the study population was high $\left(29.8 \mathrm{~kg} \mathrm{~m}^{-2}\right)$ - according to the WHO guidelines a BMI above 30 indicates the presence of obesity ${ }^{27}$.

Dietary intake of energy, fat, fatty acids and dietary fibre was comparable between the control and intervention groups. Women in the control group consumed less alcohol $(1.2 \pm 2.2 \mathrm{en} \%)$ than those in the intervention group (2.6 $\pm 4.3 \mathrm{en} \%$ ) (Table 3 ). Men in the control group consumed more fish $\left(33 \pm 43 \mathrm{~g} \mathrm{day}^{-1}\right)$ than those in the intervention group $\left(15 \pm 15 \mathrm{~g} \mathrm{day}^{-1}\right)$. In the intervention 
group more women were usual fish (92\%) and alcohol (86\%) consumers than in the control group (fish $=82 \%$, $P<0.01$; alcohol $=78 \%, P<0.05)$.

\section{Comparison of nutrient intake at baseline with the average Dutch population}

Compared to the Dutch national food consumption survey $^{16}$, the younger people in our study (22-50 years) and the older men ( $>50$ years) had a higher total fat intake. Our study population had a higher PUFA intake. Although total energy intake was also higher, the intake of energy per kilogram body weight was comparable. The women of our population reported lower alcohol consumption. Our population had a higher fruit intake at baseline (Table 4).

Underreporting of energy intake may occur more frequently by obese persons ${ }^{28}$, who comprise $42 \%$ of our study population (Table 2). The basal metabolic rate (BMR) can be estimated by equations by Goldberg et al. ${ }^{29}$. A ratio of energy intake (EI) divided by the BMR of lower than 1.0 may indicate underreporting of energy. In our population, $10.3 \%$ of the men and $15.3 \%$ of the women

Table 2 Baseline characteristics for intervention and control groups

\begin{tabular}{|c|c|c|c|c|}
\hline \multirow[b]{2}{*}{ Parameter } & \multicolumn{2}{|c|}{ Intervention group $(n=103)$} & \multicolumn{2}{|c|}{ Control group $(n=163)$} \\
\hline & Mean & SD & Mean & SD \\
\hline Age (years) & 55 & 10 & 54 & 9 \\
\hline Gender (male) (\%) & 37 & & $49^{*}$ & \\
\hline Serum total cholesterol $\left(\mathrm{mmoll}^{-1}\right)$ & 6.8 & 0.7 & 6.7 & 0.8 \\
\hline HDL cholesterol (mmoll $\left.{ }^{-1}\right)$ & 1.3 & 0.4 & 1.3 & 0.4 \\
\hline Triacylglycerol $\left(\mathrm{mmoll}^{-1}\right)^{\prime}$ & 2.1 & 1.0 & 1.9 & 1.0 \\
\hline Systolic blood pressure $(\mathrm{mmHg})$ & 146 & 23 & 144 & 22 \\
\hline Diastolic blood pressure $(\mathrm{mmHg})$ & 88 & 14 & 86 & 16 \\
\hline Hypertension (\%)† & 44 & & 36 & \\
\hline Body mass index $\left(\mathrm{kg} \mathrm{m}^{-2}\right)$ & 29.8 & 3.9 & 29.8 & 4.8 \\
\hline $\mathrm{BMI}>30 \mathrm{~kg} \mathrm{~m}^{-2}(\%)$ & 46 & & 39 & \\
\hline White blood count (cells $\left.\mathrm{nl}^{-1}\right) \ddagger$ & 7.4 & 2.1 & 7.4 & 2.1 \\
\hline \multicolumn{5}{|l|}{ Framingham $\mathrm{CHD}$ risk score $\S$} \\
\hline SBP & 15.2 & 8.5 & 15.5 & 9.5 \\
\hline DBP & 14.6 & 8.6 & 15.0 & 9.8 \\
\hline
\end{tabular}

Table 3 Baseline nutrient intake and consumption of food products, stratified for intervention condition and gender

\begin{tabular}{|c|c|c|c|c|}
\hline & \multicolumn{2}{|c|}{ Intervention group } & \multicolumn{2}{|c|}{ Control group } \\
\hline & $\begin{array}{c}\text { Men }(n=38): \\
\text { mean (SD) }\end{array}$ & $\begin{array}{c}\text { Women }(n=62) \text { : } \\
\text { mean }(S D)\end{array}$ & $\begin{array}{c}\text { Men }(n=80): \\
\text { mean }(S D)\end{array}$ & $\begin{array}{l}\text { Women }(n=82) \text { : } \\
\text { mean (SD) }\end{array}$ \\
\hline \multicolumn{5}{|l|}{ Nutrients } \\
\hline Energy (MJ day ${ }^{-1}$ ) & $11.6(3.6)$ & $9.0(2.5)$ & $12.1(3.5)$ & $8.6(2.5)$ \\
\hline Total fat (en\%) & $38.0(6.3)$ & $37.3(7.4)$ & $39.0(5.8)$ & $37.4(7.7)$ \\
\hline SFA (en\%) & $14.3(3.2)$ & $13.8(2.9)$ & $14.1(3.3)$ & $14.4(3.6)$ \\
\hline MUFA (en\%) & $12.6(2.4)$ & $12.3(2.8)$ & $13.1(2.6)$ & $12.4(2.9)$ \\
\hline PUFA (en\%) & $8.6(2.1)$ & $8.7(3.0)$ & $9.1(2.5)$ & $8.1(3.0)$ \\
\hline \multicolumn{5}{|l|}{ Alcohol } \\
\hline en\% & $4.4(4.1)$ & $2.6(4.3)$ & $4.0(4.3)$ & $1.2(2.2)^{*}$ \\
\hline$\%$ users & 95 & 86 & 94 & $78^{*}-1$ \\
\hline Dietary fibre $\left(\mathrm{g} \mathrm{day}^{-1}\right)$ & $28.6(9.2)$ & $25.2(7.1)$ & $30.8(8.3)$ & $24.5(6.4)$ \\
\hline \multicolumn{5}{|l|}{ Food products } \\
\hline $\mathrm{g}$ day $^{-1}$ & $15(15)$ & $21(22)$ & $33(43)^{\star}$ & $17(20)$ \\
\hline$\%$ users & 79 & 92 & 84 & $82^{\star \star}$ \\
\hline Red meat $\left(\mathrm{g} \mathrm{day}^{-1}\right)$ & $100(38)$ & $89(46)$ & $104(44)$ & $88(49)$ \\
\hline Poultry $\left(\mathrm{g} \mathrm{day}^{-1}\right.$ ) & $10(9)$ & $11(8)$ & $12(10)$ & $12(16)$ \\
\hline Fruit (g day ${ }^{-1}$ ) & $228(187)$ & $293(170)$ & 257 (173) & 277 (172) \\
\hline Vegetables $\left(\mathrm{g}\right.$ day $\left.^{-1}\right)$ & $140(60)$ & $138(54)$ & $156(85)$ & $134(51)$ \\
\hline Bread $\left(\right.$ g day $\left.^{-1}\right)$ & $191(114)$ & $133(43)$ & $189(71)$ & $132(44)$ \\
\hline
\end{tabular}

Differences between intervention and control groups stratified for gender, ${ }^{\star} P<0.05 ;{ }^{* \star} P<0.01$. 


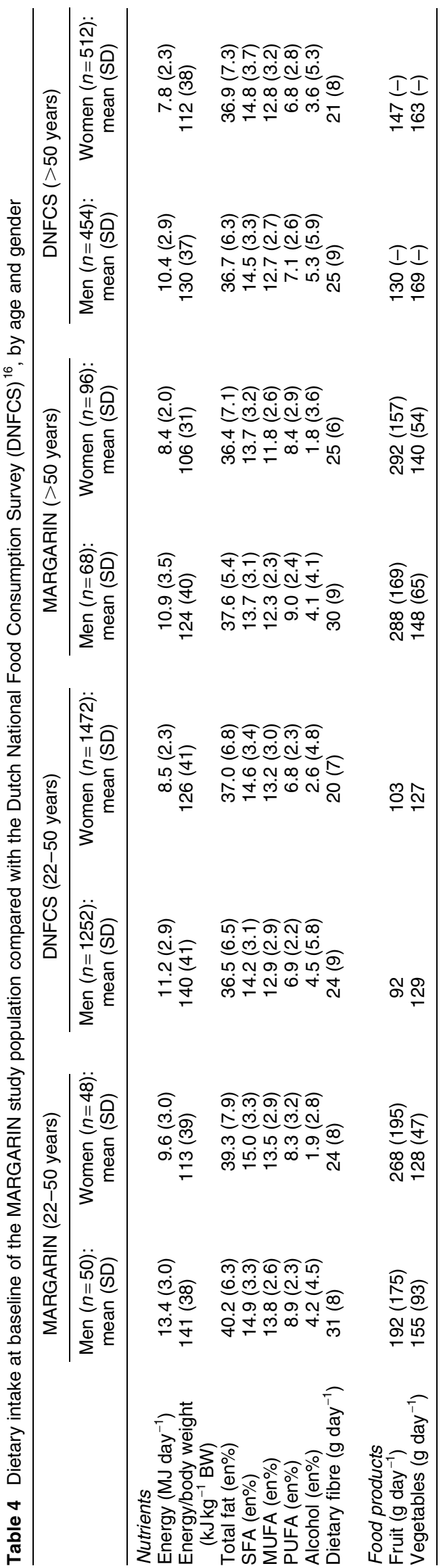

had a EI : BMR ratio lower than 1.0. In obese persons, these percentages were $16.7 \%$ and $20.3 \%$, respectively.

\section{Change in nutrient intake and dietary babits during the first year}

After 4 months, women in the intervention group decreased their total fat intake by $2.1 \mathrm{en} \%(95 \% \mathrm{CI} 0.5-$ 3.8). When data for gender were combined, the intervention group $(n=83)$ decreased their intake of total fat more than the control group ( $n=142)$ after 1 year (mean net difference $1.8 \mathrm{en} \%, 95 \% \mathrm{CI} 0.2-3.4$ ). The intervention group also decreased its SFA intake more than the control group after 1 year (mean net difference 1.2 en\%, 95\%CI 0.4-1.9).

According to the Mediterranean diet guidelines, after 4 months the intervention group increased their intake of fish $(+100 \%)$, vegetables $(+13 \%)$, bread $(+6 \%)$ and poultry $(+31 \%)$ and decreased intake of red meat $(-22 \%)$. After 1 year, intakes of fish $(+100 \%)$, bread $(+6 \%)$ and poultry $(+28 \%)$ were significantly increased in the intervention group. Table 5 shows nutrient and food intakes separately for men and women.

After 1 year the intervention group increased their intake of fruit $\left(+39 \pm 213 \mathrm{~g} \mathrm{day}^{-1}\right)$, fish $\left(+21 \pm 31 \mathrm{~g} \mathrm{day}^{-1}\right)$, poultry $\left(+4 \pm 10 \mathrm{~g} \mathrm{day}^{-1}\right)$ and bread $\left(+9 \pm 59 \mathrm{~g} \mathrm{day}^{-1}\right)$ more than the control group (fruit: $-18 \pm 159 \mathrm{~g} \mathrm{day}^{-1}$; fish: $-1 \pm 36 \mathrm{~g} \mathrm{day}^{-1}$; poultry: $0 \pm 12 \mathrm{~g} \mathrm{day}^{-1}$; bread: $-8 \pm$ $\left.51 \mathrm{~g} \mathrm{day}^{-1} ; P<0.05\right)$. After adjustment for baseline food intake, the differences in changes were still significant $(P<0.05)$. There were no significant differences in change of intake of vegetables and red meat between the intervention and control groups.

The intervention group decreased alcohol consumption during the first year (Table 5). At baseline, $24 \%$ of men and $5 \%$ of women consumed at least three alcoholic consumptions per day. After 1 year these figures were $5 \%$ of men and $2 \%$ of women. In the control group, at baseline $27 \%$ of men and $1 \%$ of women consumed at least three alcohol consumptions per day, and after 1 year $20 \%$ of men and $0 \%$ of women.

\section{Relation of fish intake to cholesteryl ester fatty acid composition}

Fish is rich in the n-3 fatty acids eicosapentaenoic acid (EPA) and docosahexaenoic acid (DHA). Dietary intake of the marine fatty acids is reflected in the fatty acid composition of the serum cholesteryl ester ${ }^{30}$. Hence, by investigating changes in the amounts of EPA and DHA in the cholesteryl ester, the reported intake of fish can be checked. In our population, Spearman correlation coefficients $(P<0.01)$ at baseline between total fish intake and amount of EPA and DHA in the cholesteryl ester were 0.41 and 0.36 (intervention group), and 0.34 and 0.34 (control group). In the intervention group, Pearson 
Table 5 Nutrient intake and consumption of food products at three measurements, stratified for gender and research condition

\begin{tabular}{|c|c|c|c|c|c|c|}
\hline & \multicolumn{3}{|c|}{ Men* } & \multicolumn{3}{|c|}{ Woment } \\
\hline & T0: mean (SD) & T16: mean (SD) & T52: mean (SD) & T0: mean (SD) & T16: mean (SD) & T52: mean (SD) \\
\hline \multicolumn{7}{|l|}{ Nutrients } \\
\hline \multicolumn{7}{|c|}{ Energy (MJ day ${ }^{-1}$ ) } \\
\hline Intervention & $11.0(3.5)$ & $10.4(3.0)$ & $10.6(3.1)$ & $9.2(2.3)$ & $8.6^{a}(1.8)$ & $8.7(2.0)$ \\
\hline Control & $12.0(3.5)$ & $11.5(3.2)$ & $11.4(2.7)$ & $8.7(2.5)$ & $8.6(2.0)$ & $8.7(2.7)$ \\
\hline \multicolumn{7}{|l|}{ Total fat (en\%) } \\
\hline Intervention & $37.3(6.0)$ & $36.2(4.7)$ & $37.9(4.6)$ & $37.4(7.4)$ & $35.2^{\mathrm{a}}(6.6)$ & $36.2(5.9)$ \\
\hline Control & $38.9(5.8)$ & $40.0(5.9)$ & $40.6^{a}(5.2)$ & $37.1(7.5)$ & $37.0(7.0)$ & $37.7(6.7)$ \\
\hline \multicolumn{7}{|l|}{ SFA (en\%) } \\
\hline Intervention & $14.0(2.8)$ & $11.5^{\mathrm{a}}(2.3)$ & $12.2^{\mathrm{a}}(1.7)$ & $13.8(3.0)$ & $11.4^{\mathrm{a}}(2.7)$ & $11.6^{\mathrm{a}}(2.3)$ \\
\hline Control & $14.0(3.1)$ & $13.0^{\mathrm{a}}(2.2)$ & $13.3^{a}(2.0)$ & $14.3(3.6)$ & $12.7^{\mathrm{a}}(2.6)$ & $13.2^{\mathrm{a}}(2.7)$ \\
\hline \multicolumn{7}{|l|}{ MUFA (en\%) } \\
\hline Intervention & $12.5(2.4)$ & $10.6^{\mathrm{a}}(1.6)$ & $11.6^{\mathrm{b}}(2.1)$ & $12.3(2.8)$ & $10.3^{a}(2.0)$ & $10.8^{\mathrm{ab}}(2.1)$ \\
\hline Control & $13.1(2.6)$ & $12.2^{\mathrm{a}}(2.3)$ & $12.2^{\mathrm{a}}(2.2)$ & $12.2(2.8)$ & $11.1^{\mathrm{a}}(2.2)$ & $11.3^{a}(2.1)$ \\
\hline \multicolumn{7}{|l|}{ PUFA (en\%) } \\
\hline Intervention & $8.5(2.1)$ & $12.4^{\mathrm{a}}(3.0)$ & $12.1^{\mathrm{a}}(2.7)$ & $8.8(3.0)$ & $11.8^{\mathrm{a}}(3.1)$ & $12.0^{\mathrm{a}}(2.9)$ \\
\hline Control & $9.2(2.5)$ & $12.8^{\mathrm{a}}(3.0)$ & $13.1^{\mathrm{a}}(2.6)$ & $8.1(3.1)$ & $11.3^{\mathrm{a}}(3.7)$ & $11.3^{\mathrm{a}}(3.2)$ \\
\hline \multicolumn{7}{|l|}{ Alcohol (en\%) } \\
\hline Intervention & $4.4(4.3)$ & $3.6(3.9)$ & $2.8^{\mathrm{a}}(3.3)$ & $2.5(4.4)$ & $2.2(3.7)$ & $1.6^{\mathrm{b}}(2.8)$ \\
\hline Control & $4.1(4.4)$ & $4.3(4.4)$ & $4.1(4.8)$ & $1.3(2.3)$ & $1.1(1.9)$ & $1.2(2.2)$ \\
\hline \multicolumn{7}{|c|}{ Dietary fibre ( $\mathrm{a} \mathrm{day}^{-1}$ ) } \\
\hline Intervention & $29(9.1)$ & $31(9.6)$ & $29(8.4)$ & $26(6.7)$ & $27(6.7)$ & $28^{a}(6.5)$ \\
\hline Control & $31(8.5)$ & $28^{\mathrm{a}}(8.9)$ & $29(8.5)$ & $25(6.3)$ & $25(6.0)$ & $25(6.4)$ \\
\hline \multicolumn{7}{|l|}{ Food products } \\
\hline \multicolumn{7}{|l|}{ Bread $\left(\mathrm{g}\right.$ day $\left.^{-1}\right)$} \\
\hline Intervention & $175(75)$ & $187^{a}(69)$ & $178(68)$ & $135(43)$ & $144(44)$ & $148^{a}(52)$ \\
\hline Control & $191(74)$ & $182(72)$ & $179(73)$ & $136(45)$ & $134(39)$ & $132(48)$ \\
\hline \multicolumn{7}{|c|}{ Vegetables (g day ${ }^{-1}$ ) } \\
\hline Intervention & $148(61)$ & $163(63)$ & $144(47)$ & $141(55)$ & $166^{\mathrm{a}}(60)$ & $152(47)$ \\
\hline Control & $156(89)$ & $145(69)$ & 149 (102) & $133(52)$ & $156^{\mathrm{a}}(63)$ & $145(54)$ \\
\hline \multicolumn{7}{|l|}{ Fruit (g day $\left.{ }^{-1}\right)$} \\
\hline Intervention & $256(195)$ & $327^{a}(176)$ & $297(170)$ & $304(171)$ & $302(134)$ & $342^{b}(180)$ \\
\hline Control & $260(176)$ & $228(186)$ & $221(163)$ & 279 (172) & 252 (167) & $283(175)$ \\
\hline \multicolumn{7}{|l|}{ Fish $\left(\mathrm{g} \mathrm{day}^{-1}\right)$} \\
\hline Intervention & $17(16)$ & $36^{a}(23)$ & $41^{a}(39)$ & $23(23)$ & $45^{a}(29)$ & $43^{a}(30)$ \\
\hline Control & $34(45)$ & 27 (22) & $23(21)$ & $18(21)$ & $25^{a}(26)$ & $26(30)$ \\
\hline \multicolumn{7}{|l|}{ Poultry (g day $\left.{ }^{-1}\right)$} \\
\hline Intervention & $10(8)$ & $15^{a}(14)$ & $13(11)$ & $11(8)$ & $16^{a}(12)$ & $15^{a}(11)$ \\
\hline Control & $11(10)$ & $10(10)$ & $10(11)$ & $11(13)$ & $13(11)$ & $11(9)$ \\
\hline \multicolumn{7}{|c|}{ Red meat ( day $^{-1}$ ) } \\
\hline Intervention & $98(40)$ & $87(34)$ & $103(49)$ & $92(46)$ & $72^{a}(27)$ & $76^{a}(31)$ \\
\hline Control & $105(46)$ & $102(45)$ & $92(37)$ & $90(52)$ & $83(44)$ & $81(37)$ \\
\hline
\end{tabular}

*Intervention group, $n=29$; control group, $n=71$.

† Intervention group, $n=54$; control group, $n=71$.

${ }^{2}$ Different $P<0.05$ from T0.

${ }^{\mathrm{b}}$ Different $P<0.05$ from T16.

correlation coefficients between the change in fish intake between baseline and T16 and the change in amounts of EPA and DHA in the cholesteryl ester were 0.22 and 0.30 , respectively $(P<0.05)$.

\section{Change in serum total cholesterol and BMI during the first year}

In the intervention group, the serum total cholesterol level decreased after 16 weeks $(2 \%, 95 \% \mathrm{CI}-0.24$ to -0.02$)$ and after 52 weeks (3\%, 95\%CI -0.31 to -0.05$)$ (T0: $6.76 \mathrm{mmoll}^{-1}$; T16: $6.63 \mathrm{mmoll}^{-1}$; T52: $6.57 \mathrm{mmoll}^{-1} ; n=$ 94). For women the decrease was $2 \%(P<0.05$; T16) and $4 \%(P<0.05 ; \mathrm{T} 52)$, and for men the decrease was $1 \%$ (NS; T16) and equal at T52 (Table 6). The decrease in serum cholesterol level was more pronounced in the group who attended at least two out of three nutritional education meetings: for these women total cholesterol decreased 3\% $(P<0.05$; T16) and $4 \%(P<0.05 ; \mathrm{T} 52)$, and for these men this decrease was $3 \%$ (NS; T16) and $1 \%$ (NS; T52). In the control group, serum cholesterol level decreased after 16 weeks $(1 \%, 95 \% \mathrm{CI}-0.15$ to 0.05$)$ and after 52 weeks $(2 \%, 95 \% \mathrm{CI}-0.22$ to -0.02$)\left(\mathrm{T} 0: 6.59 \mathrm{mmoll}^{-1}\right.$; T16: $6.55 \mathrm{mmoll}^{-1}$; T52: $\left.6.47 \mathrm{mmoll}^{-1} ; n=146\right)$. For men this decrease was $1 \%$ (NS; T16) and $2 \%$ (NS; T52), and for women this decrease was $1 \%$ (NS; T16) and $2 \%(P<0.05$; $\mathrm{T} 52)$. The net difference in change of cholesterol level at T52 between the intervention and control groups was $0.06 \mathrm{mmol}^{-1}$ (95\%CI -0.10 to 0.22 ). 
In the intervention group and in the men of the control group, BMI increased during the first year. In the women of the control group no significant change in BMI occurred (Table 6). In the intervention group, combined data showed a decrease of $-0.06 \pm 0.6 \mathrm{~kg} \mathrm{~m}^{-2}(95 \% \mathrm{CI}-0.20$ to 0.06 ) between T0 and T16, and an increase of $0.35 \pm$ $1.1 \mathrm{~kg} \mathrm{~m}^{-2}$ (95\% CI $\left.0.13-0.57\right)$ between T0 and T52. For the control group, these figures were $+0.09 \pm 0.9 \mathrm{~kg} \mathrm{~m}^{-2}$ (95\%CI -0.05 to 0.24 ) (T0 to T16) and $+0.33 \pm 1.2 \mathrm{~kg} \mathrm{~m}^{-2}$ (95\% CI 0.13-0.52) (T0 to T52). The difference in change between $\mathrm{T} 0$ and $\mathrm{T} 16$ between the intervention and control groups was significant.

\section{Relation of serum cholesterol and BMI to total and saturated fat intake}

Changes in serum cholesterol levels between baseline and T52 were not related to changes in total fat intake and were only modestly related to changes in saturated fat intake (intervention group: $r=0.23, \quad P<0.05, n=90$; control group: $r=0.15$, NS, $n=146$ ).

In the intervention group, changes in BMI between baseline and T16 were related to changes in total $(r=0.28$, $P<0.01, n=87)$ and saturated $(r=0.23, P<0.05)$ fat intake. Between baseline and T52 changes in BMI were related to changes in total $(r=0.30, P<0.01, n=90)$ and saturated $(r=0.24, P<0.05)$ fat intake. In the control group, changes in BMI were modestly related to changes in total $(r=0.13, P=0.12, n=144)$ and saturated $(r=0.09$, $P=0.3)$ fat intake.

\section{Discussion}

At baseline, compared with Dutch national food consumption survey data ${ }^{16}$, our selected high risk population had a higher PUFA intake. Due to the recruitment procedure, serum cholesterol levels were assessed 3-6 months before baseline, and knowledge of their elevated serum cholesterol level may have increased PUFA intake. The fact that $67 \%$ of the participants consumed linoleic acidenriched foods at baseline, illustrates that point. In spite of possible raised health consciousness due to our inclusion strategy, mean total fat (38 en\%) and saturated fat intake (14 en\%) at baseline were still higher than the Dutch guidelines for a healthy diet, which state a goal of $30-35$ en $\%$ and $\leqslant 10$ en $\%$, respectively.

The intensive education programme decreased total fat intake $(-0.6 \pm 6.2 \mathrm{en} \%)$ more than the usual care procedures $(+1.2 \pm 5.6 \mathrm{en} \%)$. However, in the intervention group mean total fat $(36.8 \pm 5.4 \mathrm{en} \%)$ and SFA $(11.8 \pm 2.1$ en\%) intake were still too high after 1 year. Since change in total fat intake was related to change in BMI and also to change in serum cholesterol level, decreasing total and saturated fat intake will need to be further stimulated. The interpretation of the relation between energy or total fat intake and BMI may be complicated by underreporting of 
obese people ${ }^{28}$ and differences in the amount of exercise and energy expenditure. According to the Mediterranean diet guidelines, intake of fish, fruit, poultry and bread increased more than in the control group. The intervention group significantly increased intake of fish, poultry and bread after 1 year. Intake of vegetables initially increased too, but this increase was not maintained to the 1-year follow-up. This may be caused by decreased motivation of the intervention group during the year, or by insufficient support from the social environment. Further, a lack in continued reinforcements can result in resumption of old nutritional behaviour ${ }^{31}$. Stronger personal reinforcement on increasing vegetable consumption may have been needed.

Moderate alcohol consumption is associated with reduced CVD risk ${ }^{32-34}$. Among the medical staff of the MARGARIN study some concerns existed about an increase of alcohol intake due to the intervention programme. The percentage users of over three glasses of alcohol daily dropped from $24 \%$ to $5 \%$ in men, and from $5 \%$ to $2 \%$ in women. Therefore, the guideline of $1-2$ alcohol consumptions per day for regular consumers did not lead to an increase of alcohol intake.

The intensive education programme did not lower serum cholesterol level and BMI more than the posted leaflet programme. Since in overweight people even modest weight loss is associated with reduced CVD risk $^{35}$, the education programme would have been more successful when it had succeeded in weight reduction. However, there are reasons for assuming that this approach may still be appropriate for primary CHD prevention. First, fish intake was substantially increased and long-term effects of increased fish intake may be beneficial. High fish intake is associated with low CHD mortality in high risk populations ${ }^{36}$ and a reduced risk of primary cardiac arrest ${ }^{37}$. Second, in secondary CHD prevention studies the cardioprotective effect of the Mediterranean diet or increased $\alpha$-linolenic intake was not mediated through serum lipid levels. Possible mechanisms were by preventing cardiac arrhythmias or by having an effect on blood-clotting mechanisms ${ }^{10,38,39}$. Further research is necessary to establish long-term health effects of the intensive education programme.

A weakness of the present study may be that the project margarines are unequally double-blind randomized over the intervention and control group (Table 1). The impact of $\alpha$-linolenic acid and linoleic acid on serum total cholesterol levels is similar ${ }^{40}$. Obviously the supplementation of the margarine by itself caused increased PUFA intake and a decrease of serum cholesterol level in both groups. Hence 'care as usual' actually was defined as 'care as usual plus increased PUFA intake' and this may have attenuated differences between the intervention and control groups. Further, participants who used low-fat spreads on bread before baseline replaced this low-fat spread by the freely distributed project margarines $(80 \%$ fat) during the study. These participants had to put even more effort into decreasing total fat intake and BMI. Finally, fruit and vegetable intake did not increase in the intervention group after 1 year. For fruit this can be explained by the high baseline intake. However, this high baseline level may have been caused by overestimation of the FFQ-ALA. Other research has stressed the difficulty in determining fruit and vegetable intake ${ }^{41}$.

Despite these limitations, our results are congruent with previous research. An individual advice from a dietician, research nurse or posted leaflet resulted in a serum cholesterol reduction of $1.5 \%, 2.5 \%$ and $2 \%$, respectively ${ }^{13}$. A systematic review of randomized controlled trials of multiple risk factor interventions showed a mean net difference of decrease in blood cholesterol of $0.14 \pm$ $0.01 \mathrm{mmoll}^{-1}$ between the research conditions. Furthermore, in this review interventions using personal or family counselling or education seemed to be more effective ${ }^{42}$.

We conclude that our education programme was particularly successful in increasing fish intake; compared with the control group changes in dietary behaviour were beneficial. However, after 1 year BMI increased and total fat intake was still higher than recommended. Reinforcement of the guidelines and additional attention to decreasing total and saturated fat intake is necessary. Further longitudinal research will establish the long-term effects of intensive education on other CVD risk factors and CVD events. After decoding the MARGARIN study the separate effects of $\alpha$-linolenic acid and intensive education on the Mediterranean diet on established CVD risk factors can be investigated.

\section{Acknowledgements}

This study was financially supported by Praeventiefonds grant No. 28-2757. We thank Unilever Research Laboratorium for the production and cold storage of project margarines, Nic Veeger from the Trial Coordination Center for logistic support and advice, the St Lucas Hospital in Winschoten for logistic support and accommodation of group education sessions, research dieticians Harkelien Kruijer and Sandra Hermers for preparing and executing the nutritional education programme, and participating students Houwien Reitsema, Aafie Dotinga, Mireille Ronhaar, Karin Menninga, Ineke Jonker, Marjolein Boos and Ella Bakker.

\section{References}

1 Dalstra JAA, Reitsma JB. Cardiovascular Disease in the Netherlands in 1995. Statistics of Morbidity and Mortality [in Dutch]. Den Haag: Dutch Heart Foundation, 1997.

2 Mackenbach JP, Looman CWN, Kunst AE. Geographic variation in the onset of decline of ischemic heart disease mortality in the Netherlands. Am. J. Public Health 1989; 79: 1621-7. 
3 Mackenbach JP, Kunst AE, Looman CWN. Regional differences in mortality due to ischemic heart diseases [in Dutch]. Ned. Tijdschr. Geneeskd. 1990; 134: 596-601.

4 Broer J, Wiegersma PA. Elevated mortality due to ischaemic heart disease. Exploration of available data [in Dutch]. Tijdschr. Soc. Gezondheidsz. 1993; 1: 21-6.

5 Broer J. Regional Mortality Patterns 1987-1993 [in Dutch]. Groningen: Public Health Department, 1996.

6 Bloemberg BPM, Doornbos G, van Oostrom MA. Regional Health Profiles. Presentations of Facts from Existing Registrations [in Dutch]. Bilthoven: National Institute of Public Health and Environmental Protection, 1992.

7 Lynch JW, Kaplan GA, Cohen RD, Tuomilehto J, Salonen JT. Do cardiovascular risk factors explain the relation between socioeconomic status, risk of all-cause mortality, cardiovascular mortality, and acute myocardial infarction. Am. J. Epidemiol. 1996; 144: 934-42.

8 Broer J, Wiegersma PA. Health Interview Survey 1994 and Health Interview Survey 1998 [in Dutch]. Groningen: Regional Health Service, 1994, 1998.

9 De Lorgeril M, Renaud S, Mamelle N, et al. Mediterranean alpha-linolenic acid rich diet in secondary prevention of coronary heart disease. Lancet 1994; 343: 1454-9.

10 Renaud S, Lorgeril M de, Delaye J, et al. Cretan Mediterranean diet for prevention of coronary heart disease. Am. J. Clin. Nutr. 1995; 61 (Suppl.): S1360-7.

11 Weijden T van der, Grol RPTM, Schouten BJ, Knottnerus A. Barriers to working according cholesterol guidelines. Eur.J. Public Health 1998; 8: 113-18.

12 Truswell AS, Hiddink GJ, Hautvast JGAJ. Family doctors and patients: is effective nutrition interaction possible? Eur. $J$. Clin. Nutr. 1999; 53 (Suppl. 2): 1-2 (editoral).

13 Neil HAW, Roe L, Godlee RJP, et al. Randomised trial of lipid lowering dietary advice in general practice: the effects on serum lipids, lipoproteins, and antioxidants. BMJ 1995; 310: 569-73.

14 Tang JL, Armitage JM, Lancaster T, Silagy CA, Fowler GH, Neil HAW. Systematic review of dietary interventation trials to lower total cholesterol in free-living subjects. BMJ 1998; 316: 1213-20.

15 Denke MA. Cholesterol-lowering diets. A review of the evidence. Arch. Intern. Med. 1995; 155: 17-26.

16 Hulshof KFAM, Kistemaker C, Bouman M. The Intake of Energy and Dietary Nutrients by Dutch Population Groups the National Food Consumption Survey 1997-1998 [in Dutch]. Report No. V98.805. Zeist: TNO Nutrition and Food Research Institute, 1998.

17 Rose GA, Blackburn H. Cardiovascular Survey Methods. Geneva: WHO, 1968.

18 Feunekes GIJ, Staveren van WA, Vries de JHM, Burema J, Hautvast JGAJ. Relative and biomarker-based validity of a food-frequency questionnaire estimating intake of fats and cholesterol. Am. J. Clin. Nutr. 1993; 58: 489-96.

19 Ocke MC, Bueno de Mesquita HB, Pols MA, Smit HA, Staveren van WA, Kromhout D. The Dutch EPIC food frequency questionnaire. II. Relative validity and reproducibility for nutrients. Int. J. Epidemiol. 1997; 26 (Suppl. 1): 49-58.

20 Kistemaker C, Aarnink EJM, Hulshof KFAM. The Consumption of Separate Food Products in the Netherlands, Stratified for Age and Gender [in Dutch]. TNO Report No. V93.418. Zeist: TNO Nutrition and Food Research Institute, 1993.

21 NEVO. Netherlands Food Composition Table (NEVO Table 1996) [in Dutch]. The Hague: Netherlands Centre for Nutrition Education, 1996.

22 Voskuil DW, Feskens EJM. Composition of a Food Table with Contents of Alpha-Linolenic Acid on Behalf of the Zutphen Study [ in Dutch]. National Institute of Public Health and the Environment, Report No. 441111 006. Bilthoven: National Institute of Public Health and the Environment, 1994
23 Hulshof PJM, Kosmeijer T, Zock PL, Bovenkamp van de P, Katan MB. Analyses of Foods of the Department of Human Nutrition and Epidemiology. Part 12. Margarines, Fats, Cookies and Snacks, 1996 [in Dutch]. Report No. 906754-520-1. Wageningen: Department of Human Nutrition and Epidemiology, Wageningen Agricultural University, 1996.

24 Broer J, Siero FW, Bemelmans WJE, Meyboom-de Jong B Impact of group nutrition education and surplus value of prochaska based stage-matched information on healthrelated cognitions and on Mediterranean nutrition behaviour. Submitted for publication.

25 Hoving EB, Jansen G, Volmer M, Doormaal van JJ, Muskiet FAJ. Profiling of plasma cholesterol ester and triglyceride fatty acids as their methyl esters by capillary gas chromatography, preceded by a rapid aminopropyl-silica column chromatographic separation of lipid classes. J. Chromatogr. Biomed. Appl. 1988; 434: 395-409.

26 Norušis MJ. SPSS for Windows. Base System User's Guide, Release 6.O. Chicago, USA: SPSS Inc., 1993.

27 WHO Expert Committee. Physical Status: the Use and Interpretation of Anthropometry. Technical Report Series. Geneva: World Health Organization, 1995.

28 Heerstrass DW, Ocke MC, Bueno de Mesquita HB, Peeters $\mathrm{PH}$, Seidell JC. Underreporting of energy, protein and potassium intake in relation to body mass index. Int. J. Epidemiol. 1998; 27(2): 186-93.

29 Goldberg GR, Black AE, Jebb SA, et al. Critical evaluation of energy intake data using fundamental principles of energy physiology: 1 . Derivation of cut-off values to identify underreporting. Eur. J. Clin. Nutr. 1991; 45: 569-81.

30 Zock PL, Mensink RP, Harryvan J, Vries de JHM, Katan MB Fatty acids in serum cholesteryl esters as quantitative biomarkers of dietary intake in humans. Am. J. Epidemiol. 1997; 145: 1114-22.

31 Kramish Campbell M, De Vellis BM, Strecher VJ, Ammerman AS, De Vellis RF, Sandler RS. Improving dietary behavior: the effectiveness of tailored messages in primary care settings. Am. J. Public Health 1994; 84(5): 783-7.

32 Rimm EB, Klatsky A, Grobbe D, Stampfer MJ. Review of moderate alcohol consumption and reduced risk of coronary heart disease: is the effect due to beer, wine, or spirits. BMJ 1996; 312: 731-6.

33 Kannel WB, Ellisson RC. Alcohol and coronary heart disease; the evidence for a protective effect. Clin. Chim. Acta 1996 246: 59-76.

34 Yuan JM, Ross RK, Gao YT, Henderson BE, Yu MC. Follow up study of moderate alcohol intake and mortality among middle aged men in Shanghai, China. BMJ 1997; 314 (7073): $18-23$.

35 Van-Gaal LF, Wauters MA, De-Leeuw IH. The beneficial effects of modest weight loss on cardiovascular risk factors. Int. J. Obes. Relat. Metab. Disord. 1997; 21 (Suppl.): S5-9.

36 Marckmann P, Gronbaek M. Fish consumption and coronary heart disease mortality. A systematic review of prospective cohort studies. Eur. J. Clin. Nutr. 1999; 53: 585-90.

37 Daviglus ML, Stamler J, Orencia AJ, et al. Fish consumption and the 30-year risk of fatal myocardial infarction. N. Engl.J. Med. 1997; 336(15): 1046-53.

38 Siscovick DS, Raghunathan TE, King I, et al. Dietary intake and cell membrane levels of long-chain n-3 polyunsaturated fatty acids and the risk of primary cardiac arrest. JAMA 1995; 274(17): 1363-7.

39 Singh RB, Niaz MA, Sharma JP, Kumar R, Rastogi V, Moshiri M. Randomized, double-blind, placebo-controlled trial of fish oil and mustard oil in patients with suspected acute myocardial infarction: the Indian experiment of infarct survival - 4. Cardiovasc. Drugs Ther. 1997; 11(3): 485-91. 
40 Pang D, Allman-Farinelli MA, Wong T, Barnes R, Kingham KM. Replacement of linoleic acid with alpha-linolenic acid does not alter blood lipids in normolipidaemic men. Br. J. Nutr. 1998; 80(2): 163-7.

41 Ocke MC, Bueno de Mesquita HB, Goddijn HE, Jansen A, Pols MA, Staveren van WA. The Dutch EPIC food frequency questionnaire. I. Description of the questionnaire, and relative validity and reproducibility for food groups. Int. J. Epidemiol. 1997; 26 (Suppl. 1): 37-48.

42 Ebrahim S, Smith GD. Systematic review of randomised controlled trials of multiple risk factor interventions for preventing coronary heart disease. BMJ 1997; 314: 1666-74. 